\title{
Cognitive rehabilitation in Parkinson's disease: evidence from neuroimaging
}

\section{Cristina Nombela ${ }^{1}{ }^{+}$, Pedro J. Bustillo ${ }^{2}$, Pedro F. Castell ${ }^{1}$, Lucía Sanchez $^{2}$, Vicente Medina ${ }^{2}$ and María Trinidad Herrero'}

NiCE - Clinical and Experimental Neuroscience, CIBERNED, Human Anatomy and Psychobiology Department, School of Medicine, University of Murcia, Murcia, Spain

${ }^{2}$ Radiology Department, Reina Sofía General Hospital, Murcia, Spain

Edited by:

Irene Litvan, University of Louisville

School of Medicine, USA

\section{Reviewed by:}

Cristian F. Pecurariu, University of

Transylvania, Romania

Maria Fiorella Contarino, Academic

Medical Center, Netherlands

*Correspondence:

Cristina Nombela, Cambridge University, Brain Repair Centre, E.D.

Adrian Building, Department of Clinical Neurosciences, Forvie Site, Robinson Way, Cambridge CB2 OSZ, UK.

e-mail: cn331@cam.ac.uk

${ }^{\dagger}$ Present address:

Cristina Nombela, Cambridge University, Brain Repair Centre, E.D. Adrian Building, Department of Clinical Neurosciences, Forvie Site, Robinson Way, Cambridge CB2 OSZ, UK.

\section{INTRODUCTION}

Upon its initial description in 1817, Parkinson's disease (PD) was defined as a "shaking palsy," with no reference made to any cognitive impairment (Parkinson, 1817). Many years later, cortical Lewy bodies were described in Parkinsonian patients and cognitive symptoms were added to list of symptoms (Dubois and Pillon, 1997). Nowadays, it is widely accepted that the dopaminergic denervation characteristic of PD is accompanied by alterations to other neurotransmitter systems, resulting in a wide range of cognitive (Vera-Cuesta et al., 2006) and emotional symptoms (Schiffer et al., 1988).

Classically, cognitive parkinsonian symptoms affect executive functions and more specifically, attention (Zgaljardic et al., 2003; Sammer et al., 2006). The inability to implement appropriate cognitive strategies is thought to underlie the majority of cognitive deficits observed in PD patients, leading to impaired performance in neuropsychological tests such as the Tower of London (Owen, 2004), the utilization of semantic cues (Tweedy et al., 1982), problem solving (Morris et al., 1988), conscious decision-making (Brand et al., 2004), attentional set shifting (Williams-Gray et al., 2008), and temporal ordering (Vriezen and Moscovitch, 1990).

Several specific cognitive stimulation programs have been designed to improve the cognitive capacity of PD patients. Some studies have reported improvements in patient performance using generic cognitive stimulation programs lasting 10-12 weeks (Wade et al., 2003) or 10 sessions (30 min each), which offer training in a variety of activities (Sammer et al., 2006). The use of generic neuropsychological training batteries has also been shown to improve verbal fluency, logic memory, and performance in the Raven's matrix test (Sinforiani et al., 2004), as well as information processing speed, visuospatial and visuoconstructive abilities, and executive functions, although no effects on quality of life have been described (Prats et al., 2011). Nevertheless, an improvement in some symptoms of depression has been reported in PD patients participating in cognitive programs (Dobkin et al., 2007; Charidimou et al., 2011).

In the present study, we used functional magnetic resonance imaging (fMRI) techniques to evaluate the effects of cognitive training on functional brain activation. Few studies have combined neuroimaging and attention tasks (e.g., Stroop test: Stroop, 1935) in $\mathrm{PD}$ patients to evaluate cognitive improvement after training, although the Stroop test has been used previously in conjunction with neuroimaging as a comparative tool to compare controls and patients (Rektorová et al., 2005; Vanderhasselt et al., 2006). When healthy volunteers perform the Stroop test there activation of specific areas of the brain has been detected, including the anterior cingulate/paracingulate cortex (ACC), pre-supplementary motor areas (preSMA), parietal cortex, and dorsolateral prefrontal cortex 
(DLPFC; Bench et al., 1993; Hadland et al., 2001). In ON Parkinsonian patients a specific bilateral response in the DLPFC has been reported (Fera et al., 2007). However, the relative contribution of these specific regions in the Stroop task remains unclear (MacDonald et al., 2000; Rushworth et al., 2002; Klein et al., 2005). By contrast, the subject of a continuing source of debate (MacDonald et al., 2000; Rushworth et al., 2002; Klein et al., 2005).

Here, we hypothesized that the cognitive deterioration in PD patients would be reflected by some impairment in performing the Stroop test when compared with controls. Accordingly, the patterns of brain activation associated with the test would involve a wider range of areas in PD patients than in controls. Finally, we set out to determine whether cognitive training of PD patients would improve their performance in the Stroop test and restrict the extent of brain activation.

\section{MATERIALS AND METHODS}

Ten ON state Parkinsonian patients participated in the study, which was carried out 90-120 min after the oral administration of their medication (six females and four males, mean age \pm SD: $60.5 \pm 3.45, H$ and $Y$ score $=2.5 \pm 0.5$ ). The control group was comprised of 10 age-matched volunteers (see Table 1 for demographic data and $p$ values). All participants were informed about the aims of the study and the conditions of confidentiality at a meeting, and they all gave their informed consent in accordance with the provisions of the Ethics Committee of the Reina Sofía University Hospital of Murcia (Spain) where the fMRI tests were performed.

All experimental subjects were evaluated at the beginning of the study ("first evaluation" measures) using a neuropsychological battery that covered: their clinical history; the Unified Parkinson's Disease Rating Scale (UPDRS; Fahn and Elton, 1987); the mini mental state examination (MMSE; Folstein et al., 1975); and the Montgomery Asberg Depression Rating Scale (MADRS; Asberg et al., 1978; Montgomery and Asberg, 1979). All patients received daily levodopa drugs [mean dose (mg/day) \pm SD 455 \pm 45.7 ], either alone or in combination with: a DA agonist/anticholinergic agent in two patients; Pergolide in two patients; Pramipexole, one patient.

Table 1 | Overview of the participants indicating the experimental group, subject number, demographics, and test scores.

\begin{tabular}{|c|c|c|c|c|c|c|c|c|c|c|c|}
\hline Group & Subjects & Gender & Age & $\begin{array}{l}\text { Years of } \\
\text { education }\end{array}$ & MMSE & UPDRSI & UPDRSII & UPDRS III & MADRS & Age onset & Duration \\
\hline \multirow[t]{7}{*}{ Control } & 1 & M & 64 & 8 & 30 & 0 & 0 & 0 & 4 & - & - \\
\hline & 3 & $F$ & 61 & 8 & 29 & 0 & 0 & 0 & 2 & - & - \\
\hline & 4 & $\mathrm{~F}$ & 49 & 8 & 30 & 0 & 0 & 0 & 4 & - & - \\
\hline & 5 & M & 64 & 9 & 30 & 0 & 0 & 0 & 5 & - & - \\
\hline & 8 & $\mathrm{~F}$ & 63 & 8 & 30 & 0 & 0 & 0 & 4 & - & - \\
\hline & 9 & M & 59 & 10 & 30 & 0 & 0 & 0 & 4 & - & - \\
\hline & 10 & $\mathrm{~F}$ & 57 & 9 & 30 & 0 & 0 & 0 & 2 & - & - \\
\hline Average & & & $\begin{array}{l}59.6 \pm \\
4.47\end{array}$ & $\begin{array}{l}8.8 \pm \\
1.03\end{array}$ & $\begin{array}{l}29.8 \pm \\
0.42\end{array}$ & $\begin{array}{l}0 \pm \\
0\end{array}$ & $\begin{array}{l}0 \pm \\
0\end{array}$ & $\begin{array}{l}0 \pm \\
0\end{array}$ & $\begin{array}{l}4.87 \pm \\
2.64\end{array}$ & - & - \\
\hline & 4 & $\mathrm{~F}$ & 60 & 10 & 26 & 1 & 6 & 19 & 22 & 58 & 9 \\
\hline & 5 & M & 56 & 8 & 26 & 6 & 17 & 31 & 12 & 61 & 7 \\
\hline Average & & & $\begin{array}{l}60.1 \pm \\
3.04\end{array}$ & $\begin{array}{l}7.8 \pm \\
1.48\end{array}$ & $\begin{array}{l}26 \pm \\
0.7\end{array}$ & $\begin{array}{l}3.6 \pm \\
2.79\end{array}$ & $\begin{array}{l}9.6 \pm \\
6.42\end{array}$ & $\begin{array}{l}23.6 \pm \\
8.35\end{array}$ & $\begin{array}{l}14.6 \pm \\
5.27\end{array}$ & $\begin{array}{l}61.5 \pm \\
3.08\end{array}$ & $\begin{array}{l}8.6 \pm \\
2.30\end{array}$ \\
\hline \multirow[t]{5}{*}{ PD-untrained } & 6 & $\mathrm{~F}$ & 55 & 6 & 26 & 3 & 3 & 15 & 16 & 55 & 5 \\
\hline & 7 & $\mathrm{~F}$ & 59 & 8 & 26 & 6 & 17 & 31 & 12 & 66 & 8 \\
\hline & 8 & M & 64 & 9 & 25 & 5 & 14 & 28 & 4 & 60 & 7 \\
\hline & 9 & $M$ & 63 & 7 & 26 & 3 & 8 & 14 & 14 & 61 & 10 \\
\hline & 10 & $\mathrm{~F}$ & 65 & 7 & 26 & 4 & 7 & 16 & 18 & 58 & 8 \\
\hline \multicolumn{2}{|l|}{ Average } & & $\begin{array}{l}61.2 \pm \\
4.14\end{array}$ & $\begin{array}{l}7.4 \pm \\
1.14\end{array}$ & $\begin{array}{l}25.8 \pm \\
0.44\end{array}$ & $\begin{array}{l}4.2 \pm \\
1.31\end{array}$ & $\begin{array}{l}9.8 \pm \\
5.63\end{array}$ & $\begin{array}{l}20.8 \pm \\
8.04\end{array}$ & $\begin{array}{l}12.8 \pm \\
5.40\end{array}$ & $\begin{array}{l}60 \pm \\
4.06\end{array}$ & $\begin{array}{l}7.6 \pm \\
1.8\end{array}$ \\
\hline
\end{tabular}

Subj, subjects; YoEduc, years of education; Age Onset, age at onset; Duration, duration of the disease; Controls vs. PD, comparison between controls and PD patients (trained and untrained, during the first evaluation); Trained vs. Untrain, comparison between trained and untrained PD patients during the first evaluation. 
The inclusion criteria were as follows: aged 50-80; diagnosed with PD (Foltynie et al., 2002) with onset after 40 years of age; a clinical history of symptom progression; and right-handed. Due to the methods used (fMRI techniques), subjects with metallic spectacle frames (or any piece of metal in their body) were excluded. Patients with tremor, dyskinesia, or substantial motor impairment were not considered for the study, nor were those incapable of properly using the index finger for tapping-like tasks. These specific limitations made selection of the Parkinsonian group very difficult.

In the first evaluation, all subjects were assessed with a neuropsychological battery and they completed an "easy" Sudoku $4 \times 4$ to check their competence in the task. Immediately before the scan, each subject received specific information related to the experimental task and they were allowed to become confident with the use of the three experimental buttons on the keyboard that they had to press, the keys matching the ink color (from left to right: red, blue, and green). All participants were scanned using a modified version of the Stroop paradigm. Later on, half of the PD subjects (trained-PD, $n=5$ ) voluntarily participated in the cognitive rehabilitation program while the remaining $\mathrm{PD}$ patients (untrained $\mathrm{PD}=5$ ) and the controls received no cognitive training. The cognitive training program involved performing one easy level Sudoku table at home every day for 6 months (4-by-4 grid with 2-by-2 blocks). Sudoku focuses on working memory using numerical items, while requiring no mathematical calculation. Sudoku is a conflictual task in which the user receives mutually incompatible information via rows and columns (Elser et al., 2007), and both working memory and attention are probably essential to complete this task. At weekly meetings a trained psychologist checked the Sudoku block, corrected it and explained the errors to each patient. After 6 months, all patients and controls were re-evaluated while undergoing fMRI ("second evaluation") using a parallel version of the former Stroop test that followed exactly the same procedure as in the first evaluation. No changes to the medication were made during the course of the study.

The experimental cognitive paradigm used was a modified version of the Stroop test (MacLeod, 1991; Schroeder et al., 2002; Scholes et al., 2007), which was previously tested for its suitability in a pilot phase $(n=16)$. This task consisted of "congruent" items [animal names always printed in the same color: Alce (Moose in English) written in blue ink; Rana (Frog in English) written in red ink; Visón (Mink in English) written in green ink], and "incongruent" items [color names written in incongruently colored ink: Rojo (red in English) written in green or blue ink; Verde (green in English) written in blue or red ink; Azul (Blue in English) written in red or green ink]. According to Schroeder et al. (2002) the animal name used should have the same number of letters as the color that begins with the same letter (i.e., both Rana and Rojo have four letters and begin with the letter "R," as do Visón and Verde, and Alce and Azul). The use of animal names as congruent items rather than patches of color was based on previous research suggesting that the latter were more likely to produce a Stroop facilitation effect in healthy participants (Barch et al., 1999, 2004; Barch and Carter, 2005). While based on different exercises, both the training task
(Sudoku) and the evaluation task (Stroop test) required attentionrelated skills. This allowed us to verify that any improvements observed reflected an enhancement of functional ability and that they were not simply the result of training in a specific skill.

A Siemens Symphony (1.5T) MRI system equipped for echo-planar imaging (EPI) was used for data acquisition and the EPI images were acquired using the following parameters: repetition time $=3000 \mathrm{~ms}$; echo time $(E T)=50 \mathrm{~ms}$; flip angle $=90^{\circ} ; \mathrm{FoV}=230 \times 230,128 \times 128$ matrix; and 28 contiguous slices covering the entire brain parallel to the anterior commissure-posterior commissure (AC-PC: thickness $=3.0 \mathrm{~mm}$; gap $=1 \mathrm{~mm}$; in-plane resolution $=2.5 \mathrm{~mm} \times 1.8 \mathrm{~mm} \times 5 \mathrm{~mm})$. A high-resolution 3-D anatomic set of images was collected for each participant, as well as T1-weighted images of the functional acquisition slices. The head coil set of mirrors permitted subjects to view the target, which was projected onto the opposite wall. The subject held the experimental keyboard in the right hand (LUMINA PAD from Cedrus company, model LU430-3B), which was compatible with magnetic resonance devices. Subjects could not see the three button keyboard and thus, they were required to memorize the key positions. To help the subjects relax they were shown neutral images while the anatomical sequence was applied. A BOLD functional sequence ( $9 \mathrm{~min}, 6 \mathrm{~s}$ long) was then selected and the stimuli were divided into 9 groups of 10 congruent stimuli and 9 groups of 10 incongruent stimuli, each delivered alternately in blocks. Each of the stimuli lasted for 3,000 ms, during which time the subject had to reply by pressing the correct key (Figure 1). No feedback was provided to the subjects.

All time series were converted into statistical parametric maps (SPM) and subsequently analyzed using the SPM5 package (Wellcome Department of Cognitive Neurology, London, UK). Studies were visually inspected for artifacts such as ghosting and a six parameter rigid body transformation was used for image realignment (three rotations and three translations). The realigned databases were normalized with a Talairach frame (Talairach and Tournoux, 1988), applying a 12 parameter affine transformation and a voxel size of $3 \mathrm{~mm} \times 3 \mathrm{~mm} \times 3 \mathrm{~mm}$. An 8 - $\mathrm{mm}$ full-widthhalf-maximum (FWHM) isotropic Gaussian kernel was used to smooth the data. The data were also screened to ensure high quality, as demonstrated by small motion correction (all patients displayed the following parameters: $2 \mathrm{~mm}$ translation displacement, $1^{\circ}$ rotation). Predetermined condition effects at each voxel were calculated using $t$-statistics, producing a statistical image for "Incongruent" and "Congruent" vs. control/trained-PD/untrained PD contrasts, and for "Incongruent" vs. "Congruent," in a subjectspecific fixed effect model. The statistical images generated for the contrasts were then entered into a one-sample $t$-test model (random-effects analysis) to explore the main effect of the tasks for each individual contrast ( $p=0.005$ corrected, cluster size $K=10$ voxels) and for each group (trained-PD, untrained $\mathrm{PD}$, and controls). In the SPM analysis a $p$ value of 0.05 was taken as the activation threshold for each comparison. First level model analysis was carried out considering the condition "item-type" (with two levels: incongruent items and congruent items) in each group. Second level analysis was performed considering two conditions: (i) Item-type (with two levels: incongruent items and congruent 
items), and (ii) Group (Control, trained-PD, and untrained PD patients).

\section{BEHAVIORAL ANALYSIS}

$t$-Tests were carried out for both the "first evaluation" and "second evaluation," considering the variable "groups" and with three levels (control vs. Trained-PD and Untrained PD). All test scores (MMSE, MADRS, UPDRS, Sudoku latency, and Stroop responses) were analyzed in all three groups with the level of significance set at $p<0.05$. Following this, Bonferroni's correction was applied to significance values. Sudoku scores corresponded to the valuation made just before the scan session, while the Stroop scores correspond to the data obtained during the scan session. The scores of neuropsychological tests were corrected for age, gender, and education.

\section{RESULTS \\ QUESTIONNAIRE SCORES}

Both the results of the first and second evaluations are presented considering the three different groups studied (controls, trained, and untrained patients), although during the first evaluation there was just one group of patients. Scores have been analyzed by splitting the group in two (trained and untrained patients) to enable the groups in the first evaluation to be compared with those in the second evaluation.

There were significant differences in the MADRS scores between patients and controls in the first evaluation $\left(\bar{X}_{\text {control }}=\right.$ $4.87 \pm 2.64$ vs. $\bar{X}_{\mathrm{PD}}=13.71 \pm 5.64 ; p \leq 0.05$; Figure 2 ). Moreover, the scores in MMSE were significantly lower in both the $\mathrm{PD}$ patient groups than in the healthy subjects $\left(\bar{X}_{\text {control }}=\right.$ $29.78 \pm 0.22$ vs. $\bar{X}_{\text {trained }-\mathrm{PD}}=26 \pm 0.41$ vs. $\bar{X}_{\text {untrained }} \mathrm{PD}=$ $25.75 \pm 0.25 ; p \leq 0.001)$, although there was no significant difference between the trained and untrained PD patients $(p>0.005$, Table 1). With respect to the Sudoku puzzles, PD patients needed significantly more time to solve an "easy" Sudoku (measured in seconds) than the controls (mean $\pm \mathrm{SD} ; \bar{X}_{\text {control }}=$ $3.5 \mathrm{sec} \pm 0.52$ vs. $\bar{X}_{\text {trained - PD }}=26.2 \mathrm{sec} \pm 6.43$ vs. $\bar{X}_{\text {untrained }} \mathrm{PD}=$ $27.7 \mathrm{sec} \pm 10.18 ; p \leq 0.001$ corrected; Table 2 ). However, when the two PD patient groups were compared there were no significant differences in the UPDRS subscale I, although the scores for both types of PD patient were significantly higher than those of the control subjects in the UPDRS subscale I $\left(\bar{X}_{\text {control }}=\right.$ $0.0 \pm 0$ vs. $\bar{X}_{\text {trained }} \mathrm{PD}=3 \pm 2.82$ vs. $\bar{X}_{\text {untrained }} \mathrm{PD}=4 \pm 1.14$

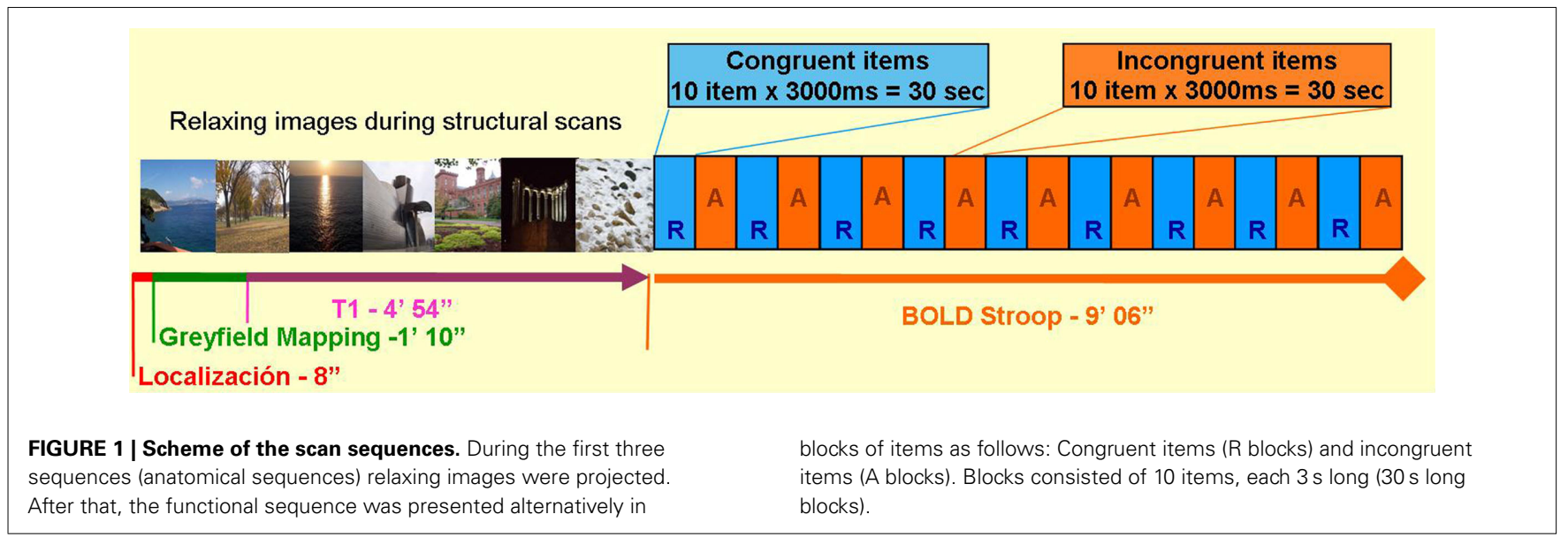

\section{MADRS score}

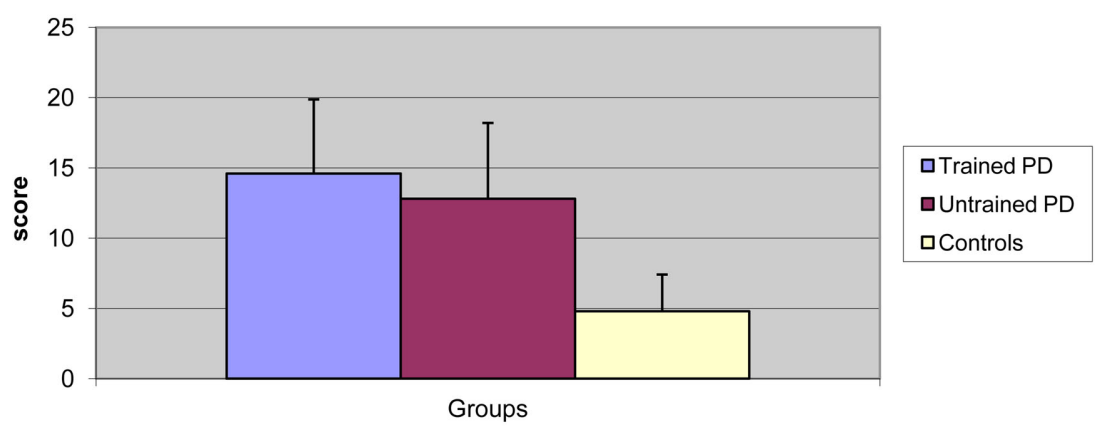

FIGURE 2 | Montgomery Asberg Depression Rating Scale scores from control subjects and patients (trained and untrained) at the first evaluation demonstrating the significant differences between both groups $(p>0.001)$. 
$p>0.001)$, subscale II $\left(\bar{X}_{\text {control }}=0.0 \pm 0\right.$ vs. $\bar{X}_{\text {trained }} \mathrm{PD}=$ $9.27 \pm 5.67$ vs. $\left.\bar{X}_{\text {untrained }} \mathrm{PD}=10.75 \pm 6.38 ; p>0.001\right)$ and subscale III ( $\bar{X}_{\text {control }}=0.0 \pm 0$ vs. $\bar{X}_{\text {trained }} \mathrm{PD}=21.75 \pm 8.38$ vs. $\bar{X}_{\text {untrained }} \mathrm{PD}=23.25 \pm 6.63 ; p>0.001$; Table 1; Figure 3).

During the second evaluation untrained PD patients needed significantly more time to solve an "easy" Sudoku (measured in seconds) than trained-PD patients or controls (mean $\pm \mathrm{SD}$; $\bar{X}_{\text {control }}=3.22 \mathrm{sec} \pm 0.33$ vs. $\bar{X}_{\text {trained }-\mathrm{PD}}=18 \mathrm{sec} \pm 4.9$ vs. $\bar{X}_{\text {untrained }} \mathrm{PD}=27.1 \mathrm{sec} \pm 9.12 ; p \leq 0.001$ corrected: Table 2 ).

\section{STROOP TEST SCORES}

The reaction times (RT, ms) in the first evaluation differed significantly between the control and PD patient groups $\left(\bar{X}_{\text {control }}=\right.$
$897.6 \pm 192$ vs. $\bar{X}_{\text {trained }} \mathrm{PD}=1130.42 \pm 283$ vs. $\bar{X}_{\text {untrained }} \mathrm{PD}=$ $1232.33 \pm 345 ; p \leq 0.001$; Figure 2), whereas no differences were observed between the groups in terms of the number of correct responses $\left(\bar{X}_{\text {control }}=59.67 \pm 0.27\right.$ vs. $\bar{X}_{\text {trained }} \mathrm{PD}=52.42 \pm 1.83$ vs. $\left.\bar{X}_{\text {untrained }} \mathrm{PD}=45.33 \pm 14.45 ; p \geq 0.05\right)$, the number of incorrect responses $\left(\bar{X}_{\text {control }}=0.41 \pm 2.66\right.$ vs. $\bar{X}_{\text {trained }} \mathrm{PD}=2.75 \pm 1.83$ vs. $\left.\bar{X}_{\text {untrained }} \mathrm{PD}=5.73 \pm 2.75 ; p \geq 0.05\right)$ or the number of missing responses $\left(\bar{X}_{\text {control }}=0.88 \pm 0.91\right.$ vs. $\bar{X}_{\text {trained }} \mathrm{PD}=1.6 \pm 1.83$ vs. $\bar{X}_{\text {untrained }} \mathrm{PD}=8.33 \pm 4.45 ; p \geq 0.05$ : Table 2 ).

In the second evaluation, there were significant differences in the Stroop task reaction times between the two groups of PD patients $\left(\bar{X}_{\text {trained }} \mathrm{PD}=955 \pm 173\right.$ vs. $\bar{X}_{\text {untrained }} \mathrm{PD}=1154 \pm 252$; $p \leq 0.01$ ), as well as between both PD patient groups and the

Table 2 | Mean Stroop scores (correct, incorrect, missing answers, and reaction time) in PD and controls from the first and second evaluation.

\begin{tabular}{|c|c|c|c|c|c|}
\hline & Correct & Incorrect & Missing & RT & SUDOKU \\
\hline \multicolumn{6}{|l|}{ 1ST EVALUATION } \\
\hline Control & $43.33 \pm 0.27$ & $0.41 \pm 2.66$ & $0.08 \pm 0.91$ & $397.6+192$ & $3.5 \pm 0.52$ \\
\hline Untrain-PD & $52.42 \pm 14.45$ & $5.73 \pm 2.75$ & $8.33 \pm 4.45$ & $1232.33 \pm 345$ & $27.7 \pm 10.18$ \\
\hline Control-PD ( $p$ value) & 0.07 & 0.06 & 0.11 & 0.001 & 0.001 \\
\hline Control & $59.53 \pm 0.31$ & $1.5 \pm 1.89$ & $0 \pm 0$ & $891 \pm 199$ & $3.22 \pm 0.33$ \\
\hline Train-PD & $58.42 \pm 1.83$ & $1.41 \pm 1.5$ & $0.16 \pm 0.33$ & $955 \pm 173$ & $18 \pm 4.9$ \\
\hline Untrain-PD & $53.33 \pm 14.45$ & $2.25 \pm 3.61$ & $4.75 \pm 4$ & $1154 \pm 252$ & $27.1 \pm 9.12$ \\
\hline Control-PD ( $p$ value) & 0.08 & 0.38 & 0.44 & 0.001 & 0.001 \\
\hline Train-untrained ( $p$ value) & 0.04 & 0.21 & 0.00 & 0.01 & 0.05 \\
\hline
\end{tabular}

On both occasions, significant differences were observed between controls and PD patients in Stroop RT ( $p \leq 0.001)$ and Sudoku speed ( $p \leq 0.001)$. Additional differences were observed in the second evaluation only between trained and untrained $P D$ patients regarding the numbers of correct and missing answers $(p \leq 0.05$, $p \leq 0.001$, respectively), and the $R T(p \leq 0.01)$ in the Stroop test, and in the Sudoku solving time $p \leq 0.05$.

\section{UPDRS scores in PD patients}

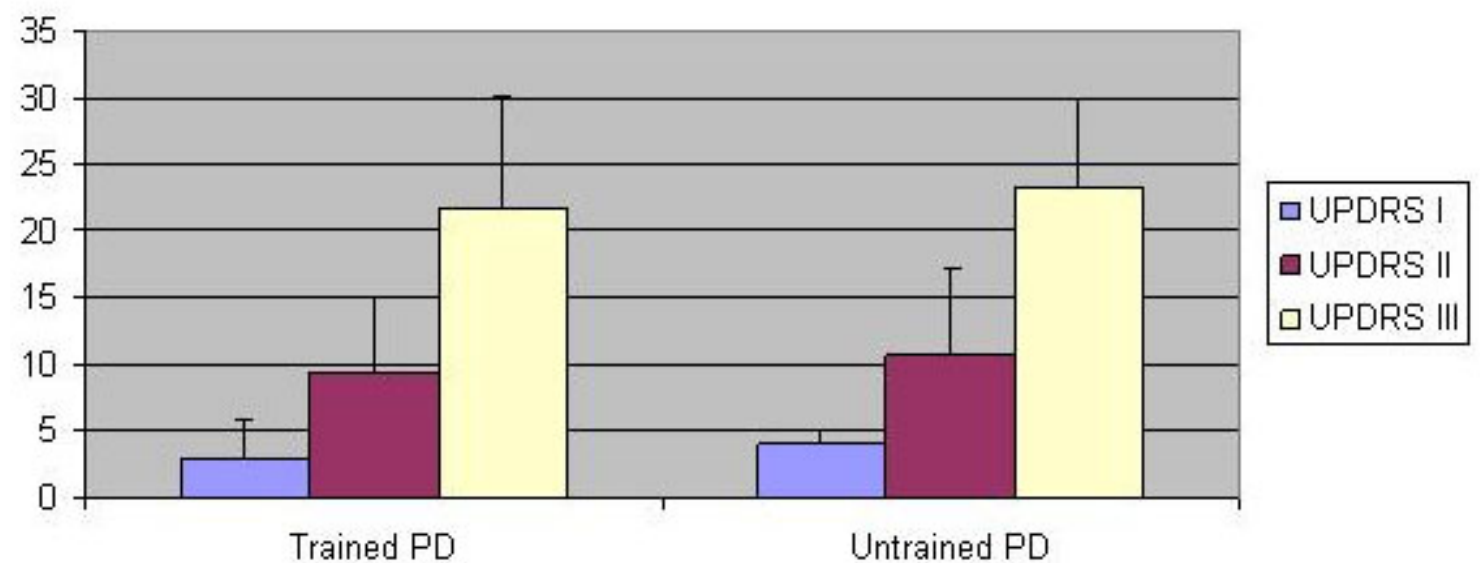

FIGURE 3 | The subjects UPDRS scores during the study (first evaluation). There were significant differences between the two groups of patients. 
control subjects $\left(\bar{X}_{\text {control }}=891 \pm 199, p \leq 0.001\right)$. The number of correct $\left(\bar{X}_{\text {control }}=59.58 \pm 0.31\right.$ vs. $\bar{X}_{\text {trained }} \mathrm{PD}=58.42 \pm 1.83$ vs. $\left.\bar{X}_{\text {untrained }} \mathrm{PD}=52.33 \pm 14.45 ; p \geq 0.005\right)$, incorrect $\left(\bar{X}_{\text {control }}=\right.$ $1.5 \pm 1.89$ vs. $\bar{X}_{\text {trained }} \mathrm{PD}=1.41 \pm 1.5$ vs. $\bar{X}_{\text {untrained }} \mathrm{PD}=$ $2.25 \pm 3.61$

$p \geq 0.005)$ and missing responses $\left(\bar{X}_{\text {control }}=0 \pm 0\right.$ vs. $\bar{X}_{\text {trained }} \mathrm{PD}=0.16 \pm 0.33$ vs. $\bar{X}_{\text {untrained }} \mathrm{PD}=4.75 \pm 4 ; p \geq 0.005$ ) did not differ significantly between any group of subject in the second evaluation (Table 2). Finally, there was a significant difference in the RT between the first and second evaluation of PD trained patients $(p \geq 0.05)$, and in the correct $(p \geq 0.05)$ and missing answers $(p \geq 0.01)$ during the Stroop task, but not in the incorrect answers $(p \geq 0.05)$.

\section{BRAIN ACTIVATION}

During the first evaluation, the control group exhibited a classical activation pattern associated with the Stroop test, specific to incongruent $>$ congruent activations. This pattern involves the bilateral anterior cingulate cortex, right superior parietal cortex, and left superior temporal gyrus, as well as additional areas, such as the left inferior temporal gyrus, right cuneus gyrus, and left precuneus gyrus. During the task, the PD patients (trained and untrained) exhibited extensive activation throughout the cortex, involving the bilateral superior frontal gyri, left inferior parietal gyrus, bilateral parahippocampal gyri, left superior temporal gyrus, right putamen and globus pallidum, and the left tail of the caudate nucleus (see Table 3 for more detailed information). The differences in the activation pattern between controls and PD patients (control $>\mathrm{PD}$ ) principally involved the left precentral gyrus, left medial frontal gyrus, right precuneus, and left inferior parietal gyrus. When the brain activation patterns between trained and untrained PD patients during the first evaluation were compared there were no significant differences $(p=0.05)$.

The results of the second evaluation revealed that in untrained PD patients there was significantly stronger activation of areas such as the right putamen, left ventrolateral prefrontal cortex, left frontal superior gyrus, right frontal medial gyrus, left superior temporal gyrus, left precuneus gyrus, bilateral cuneus gyri, left angular gyrus, and left lingual gyrus, when compared with the trained PD patients $(p=0.05)$. By contrast, in trained PD patients there was stronger activation in the right superior and medial temporal gyri than in untrained $\mathrm{PD}$ patients $(p=0.05$ see comparisons in Figure 4). Moreover, there were no significant differences in the brain activation of the control subjects between the first and second evaluation $(p=0.05)$.

When the activation pattern during the second evaluation was compared between controls and trained PD patients (control $>$ trained PD), the latter showed greater activation of right anterior cingular gyrus, left inferior frontal gyrus, right medial frontal gyrus, left angular gyrus, left precuneus gyrus, right supramarginal gyrus, left superior parietal gyrus, right medial temporal gyrus, left parahippocampal gyrus, and left insula and thalamus.

\section{DISCUSSION}

In the present study, PD patients that completed a cognitive training program showed significant improvements in reaction time when performing an attention task, which corresponded with attenuated pattern of brain activation. "Interestingly, in Stroop task, the number of correct responses in trained patients did not improve in the second evaluation, while missing responses were significantly reduced and incorrect responses improved. Differences in correct responses between first and second evaluation were not statistically significant. This lack of improvement in correct responses could be due to the no effect of the training on that aspect of the Stroop task." No differences in the neuropsychological assessment (UPDRS, MMSE, Stroop scores, and reaction time) or brain activation were observed between the two PD groups during the initial evaluation. However, after training those who participated in the program had significantly faster reaction times, approximating to the scores of the control subjects, and with significant alterations in their pattern of brain activation. Indeed, in untrained patients there was an over-activation of the frontal, temporal, and parietal areas when compared with the trained patients. Hence, the changes observed in the trained patients (when comparing first and second evaluation) appear to be linked to the concomitant alterations in brain activity, reflecting the effects of the cognitive training. Previous studies have linked cortical over-activation in PD to the depletion of neurotransmitters, including dopamine, noradrenaline, serotonin, and their metabolites (Scatton et al., 1983). In fact, abnormal neurotransmitter levels are associated with the impairment of inhibitory and excitatory cortical processes. Cortico-cortical connections are thought to depend on the inhibitory capacity of the cortex, which is impaired in Parkinsonian patients (Bares et al., 2003; McNamara et al., 2007). Thus, it is plausible that impairment of cortical inhibition could result in the inappropriate activation of certain brain areas, consistent with the broader pattern of activation in PD patients than in controls. Such impairments may also account for the slowness observed in PD patients during task resolution.

In agreement with previous studies, the key differences in the basic activation pattern observed between PD patients and controls when performing the Stroop test involved the activation of the DLPFC and basal ganglia, two regions strongly affected by dopamine depletion in PD, as well as the fronto-parietal circuitry. In the early stages of $\mathrm{PD}$, the greatest reduction in dopamine is observed in the dorsal striatum, which primarily projects to the DLPFC, while the ventral striatum that projects to the ACC and orbitofrontal cortex is less affected (Cohen et al., 2000). The DLPFC is sensitive to the presence of conflict when a top-down modulation of posterior processing areas is needed to guide response selection toward task relevant information (Liu et al., 2006), as occurs in the Stroop test. Increased activation was also observed in the basal ganglia of PD patients when compared with controls (right putamen and globus pallidum, and left caudate nucleus tail), which was probably related to the effects of medication (Carey et al., 1995). Dopaminergic drugs are associated with an "inverted U" effect, whereby too much or too little dopamine can decrease PD patients' performance. This effect does not depend on the neuropsychological specificity of the drug, disease duration, or severity but rather, on cognitive demands (Cools et al., 2001). Finally, under healthy conditions the Stroop task requires a group of fronto-parietal circuits 
Table 3 | Activation related to the training condition in controls and trained or untrained PD patients during the Stroop test in both the first and second evaluation $(p=0.05)$.

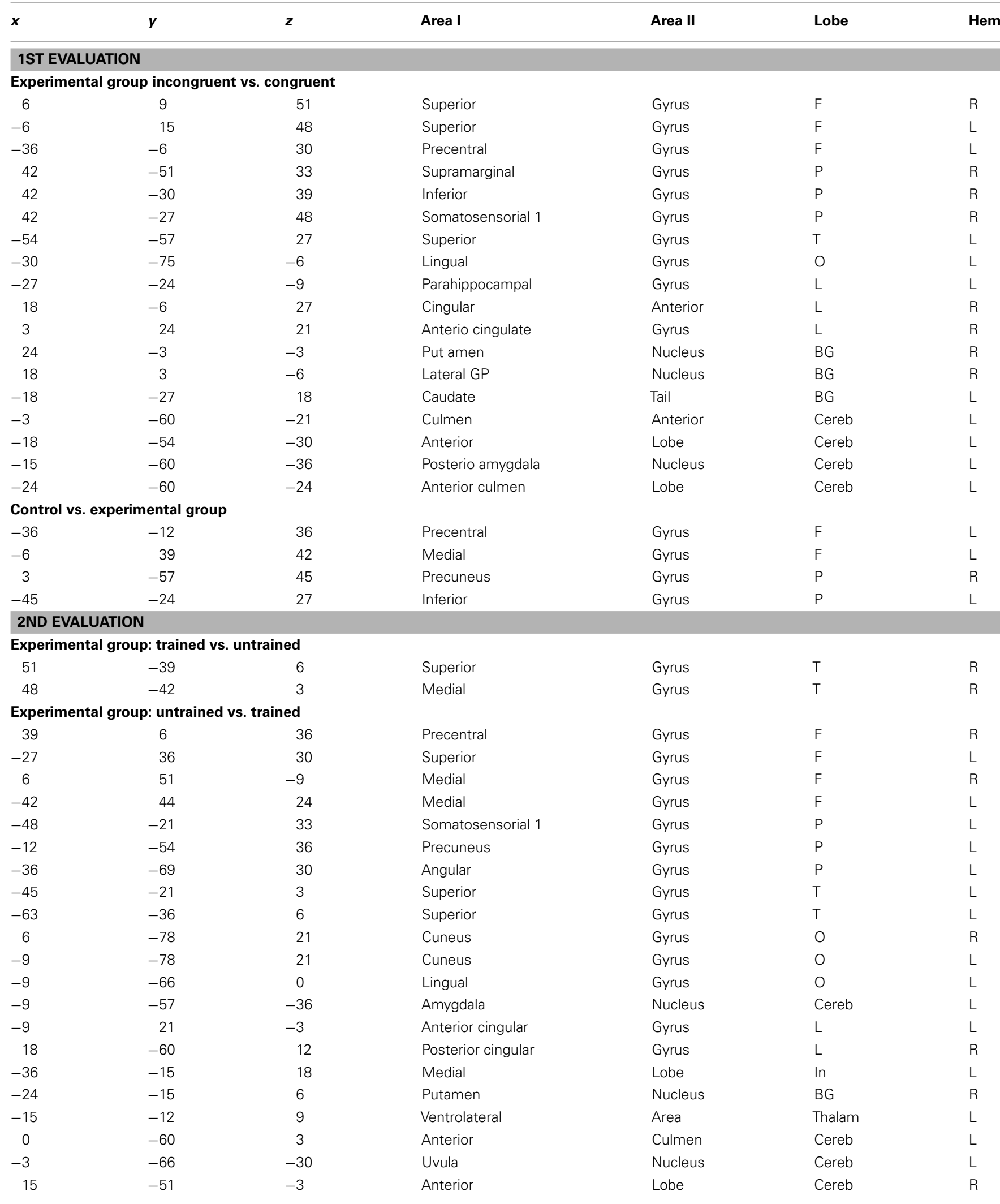

Experimental group: PD patients group (Trained and untrained). 


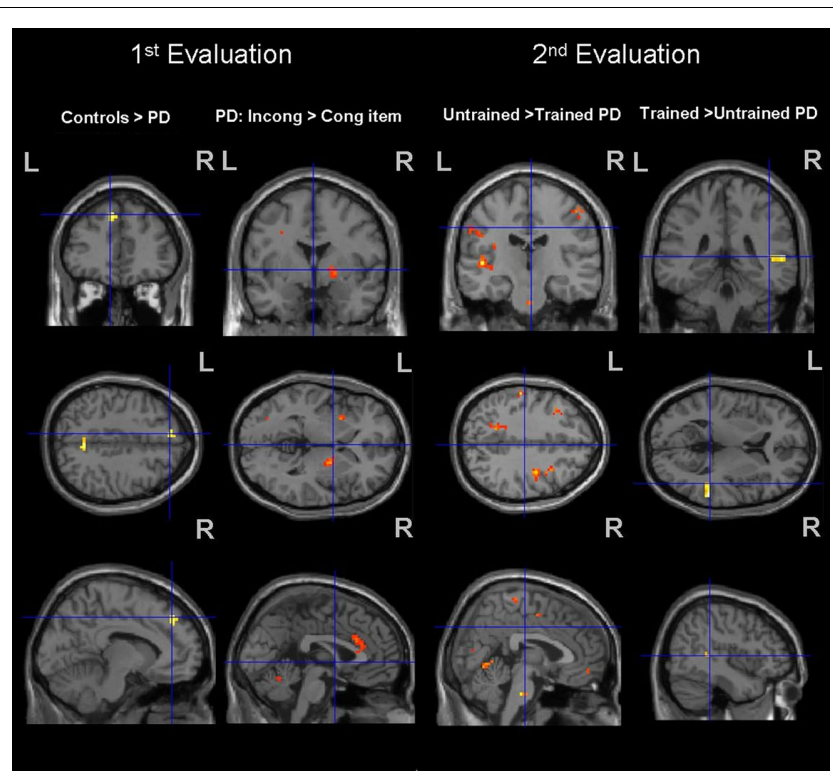

FIGURE 4 | Brain activation as evident in the SPM comparative analysis. Anatomically defined marks were used to display the activation in the regions of interest (ROIs) using the Talairach and Tournoux (1988) atlas tool in SPM2. The results are shown for: (i) the first evaluation (the first two columns on the left): control group > PD at solving incongruent items, and PD patients at solving incongruent items; the second evaluation (the first two columns on the right), trained with respect to untrained patients and untrained with respect to trained patients. There is a different pattern of activation between both groups that reflects the effect of the training program.

specialized in "conflict detection" and "conflict adaptation" (Egner and Hirsch, 2005). This function relies on the frontal regulation of attention, mediated by the frontal cortex itself. The frontal cortex receives dopamine projections from the mesocortical pathway (Alexander et al., 1986) and it is critically involved in cognitive and emotional tasks. The degeneration of these projections and the consequent hypofunction of the prefrontal cortex have been previously well defined in PD (Stam et al., 1993; Braak et al., 2004).

The pattern of brain activation in each PD group and the control subjects corresponded to those described classically (Cohen et al., 1990; Pardo et al., 1990; Carter et al., 1995, 2000; MacLeod and Dunbar, 1988; Doder et al., 1999; Peterson et al., 1999; Barch et al., 2001; Milham et al., 2001, 2002; Kerns et al., 2004; Langenecker et al., 2004; Harrison et al., 2005; Brown and Eyler, 2006; Fera et al., 2007; Lewis et al., 2008). The concordance in the brain activation patterns observed while performing the Stroop test and those in previous studies further validates the use of this version of the test for this type of evaluation (Schroeder et al., 2002). Indeed, we observed no significant differences in Stroop scores between PD patients and controls, as seen previously (Brown and Marsden, 1991; Brück et al., 2005). Distinct patterns of brain activation between controls and patients appeared in both the first and second evaluation, and they become more complex after training, involving more brain areas (mostly frontal and parietal). These areas are associated with the classical Stroop pattern that has been described previously (Cohen et al., 1990). In fact, there was an over-activation of the frontal, temporal, and parietal areas in trained PD patients with respect to untrained patients, and the recruiting of these areas is compulsory to perform the Stroop task, as described classically under healthy conditions, albeit to a lesser extent (MacLeod and Dunbar, 1988). This is again another example of the problem of cortical inhibition that, even under training conditions, can partially improve but still persists in PD brains.

It could be argued that the PD patients and healthy controls exhibited similar activation patterns, although the activation in the latter group was less intense, probably reflecting the correct inhibitory cortical activity. This issue was addressed further by considering the results of the second evaluation. In order to verify the differences in activation during the Stroop task across all three groups, a first level analysis in SPM was run considering different $p$ values (from 0.001 to 0.009 , each indicated by a different color) and using FDR correction (Figure 5). When different levels of restriction were considered (being more or less liberal in the selected criteria), activation patterns differed in all three groups after training. One persistent characteristic is that PD patients recruited more areas to solve the task, and even more in untrained patients than in trained ones, these results confirm the significance of the differences in brain activation in $\mathrm{PD}$ patients. Impaired cortico-cortical connections have been described in PD (McNamara et al., 2007) and their effects are ameliorated by levodopa/dopaminergic medication, in conjunction with the relief of clinical symptoms (Lefaucheur, 2005). Although both PD groups were ON medication, the effect of the training ameliorated the differences between $\mathrm{PD}$ trained patients and controls, as shown by the altered patterns of brain activation.

To date, there is no standardized program to quantify cognitive impairment in PD patients. We would propose that Sudoku training may contribute to improve the cognitive strategies used by PD patients in problem solving, improving their ability to generate internally applicable rules. Such training helps facilitate effective cognitive behavior demands, inductive reasoning, and spontaneous cognitive flexibility, processes that are typically impaired in PD (Goebel et al., 2010) and susceptible to improvement by training. To the best of our knowledge, this is the first study to investigate the potential of Sudoku tasks in cognitive training, which may represent an interesting tool for cognitive conflict research. An adequate cognitive strategy requires the retention of decision-making information in the working memory, which in turn involves the inhibition of irrelevant information. As such, training in the development of internal strategies for conflict resolution should improve the performance of PD patients in these types of tasks.

Given the small sample size involved, which reduced the statistical power of our analyses, our data should be interpreted with caution, even though several previously published neuroimaging studies have included nine or even fewer PD patients (George et al., 1993; Owen et al., 1998; Whalen et al., 1998; Doder et al., 1999; Langenecker et al., 2004; van Veen and Carter, 2005; Marié et al., 2007; Monchi et al., 2007; Lewis et al., 2008). The pathology and typical aging problems [such as visual, motor 


\section{LEFT HEMISFERE}

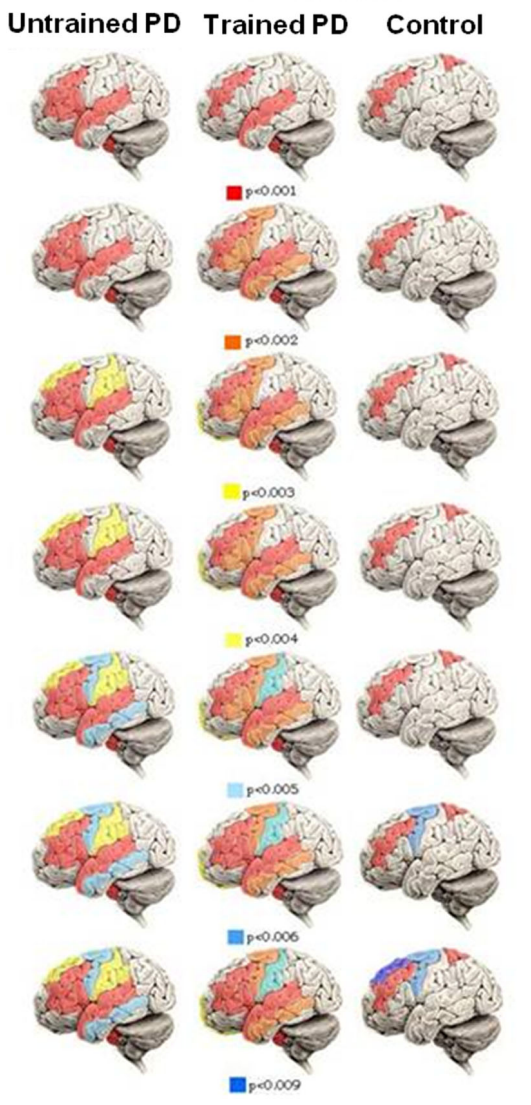

FIGURE 5 | Brain activation in PD patients and controls. The analysis considers different $p$ values (ranging from 0.009 to 0.001 ). Each color represents the brain areas in which significant differences were observed at each $p$ value considered. The top line shows the results for $p<0.001$ (red areas), while the second line shows the areas activated considering $p<0.002$ (orange) plus the previous ones (blue areas that were activated at $p<0.001$ ),

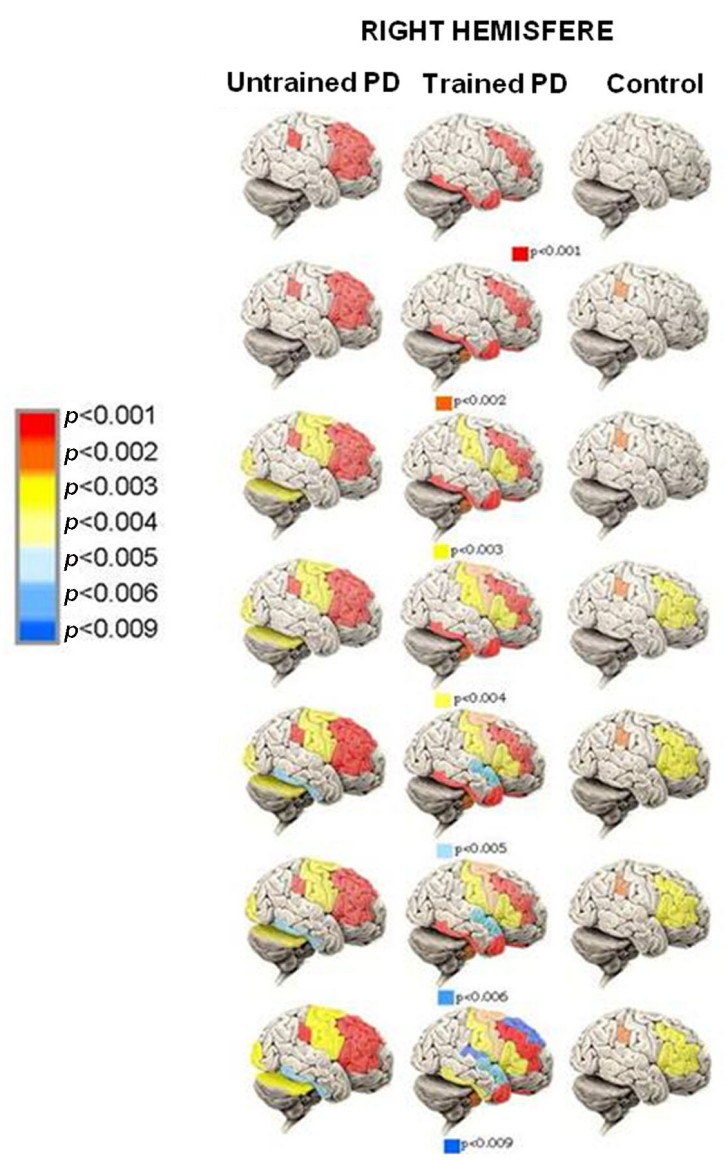

and so on for $p$ values up to 0.009 . At $p$ values equal to 0.009 a significant increase in the number of activated areas was still evident when compared with the controls (control $>$ trained $>$ untrained), as also occurred at $p=0.001$. One permanent characteristic is that PD patients require the recruitment of more areas to solve the task, and more in untrained patients than in trained ones, confirming the differences that training had on these patients. (tremor), and dystonic impairments] found in these patients significantly complicates the generation of larger study groups, an issue that should be addressed in future studies. Interestingly, the 6-month cognitive training period (based on Sudoku exercises) undertaken by the PD patients appeared to have a medium term effect, as determined by the Stroop RT and accuracy, as well as a positive effect on brain activity, producing a significant reduction in cortical activation while performing the Stroop task. These improvements appear to reflect a change in functional patterns corresponding to the training. However, it is also important to stress that patients were not randomized to be trained and untrained and that there might be a bias vs. more "cognitively capable" patients choosing to do the Sudoku training.

Although no proved by current data, we speculate that former improvement in cognitive performance and the changes in brain activation could probably have a positive effect on patients' UPDRS score. Cognitive features are briefly assessed in UPDRS I so that training would improve the score in that subscale. Regarding the motor subscale, improving cognitive abilities could also have a positive effect on motor features due to both higher motivation of the patient (given their improved ability to deal with different situations) and the reactivation of brain pathways through cognitive training (as some cognition and motor planning takes place in frontal areas).

For all these reasons we suggest that a standardized cognitive program should be considered as routine therapy for Parkinsonian patients, to be applied in combination with motor therapy, as has been effectively demonstrated for other pathologies such as stroke (Rand et al., 2010).

\section{ACKNOWLEDGMENTS}

We wish to thank all the participants for their valuable contribution and nurses at the Reina Sofia University Hospital for their support and assistance with the study. We also thank the SAI (University of Murcia) for their assistance during the analysis. This study was supported by a University of Murcia PhD grant. 


\section{REFERENCES}

Alexander, G. E., DeLong, M. R., and Strick, P. L. (1986). Parallel organization of functionally segregated circuits linking basal ganglia and cortex. Annu. Rev. Neurosci. 9, 357-381.

Asberg, M., Montgomery, S. A., Perris, C., Schalling, D., and Sedvall, G. (1978). A comprehensive psychopathological rating scale. Acta Psychiatr. Scand. Suppl. 271, 5-27.

Barch, D. M., Braver, T. S., Akbudak, E., Conturo, T., Ollinger, J., and Snyder, A. (2001). Anterior cingulated cortex and response conflict: effects of response modality and processing domain. Cereb. Cortex 11, 837-848.

Barch, D. M., and Carter, C. S. (2005). Amphetamine improves cognitive function in medicated individuals with schizophrenia and in healthy volunteers. Schizophr. Res. 77, 43-58.

Barch, D. M., Carter, C. S., Hachten, C., Usher, M., and Cohen, J. D. (1999). The benefits of distractibility: mechanisms underlying increased stroop effects in schizophrenia. Schizophr. Bull. (Bp) 25, 749-762.

Barch, D. M., Cohen, J. D., and Carter, C. S. (2004). Factors influencing Stroop performance in schizophrenia. $\mathrm{Neu}$ ropsychology 18, 477-484.

Bares, M., Kanovský, P., Klajblová, H., and Rektor, I. (2003). Intracortical inhibition and facilitation are impaired in patients with early Parkinson's disease: a paired TMS study. Eur. J. Neurol. 10, 385-389.

Bench, C. J., Frith, C. D., Grasby, P. M., Friston, K. J., Paulesu, E., Frackowak, R. S., and Dolan, R. J. (1993). Investigations of the functional anatomy of attention using the Stroop test. Neuropsychology 31, 907-922.

Braak, H., Ghebremedhin, E., Rüb, U., Bratzke, H., and Del Tredici, K. (2004). Stages in the development of Parkinson's disease-related pathology. Cell 318, 121-134.

Brand, M., Labudda, K., Kalbe, E., Hilker, R., Emmans, D., Fuchs, G., Kessler, J., and Markowitsch, $\mathrm{H}$. J. (2004). Decision-making impairments in patients with Parkinson's disease. Behav. Neurol. 15, 77-85.

Brown, G. G., and Eyler, L. T. (2006). Methodological and conceptual issues in functional magnetic resonance imaging: applications to schizophrenia research. Annu. Rev. Clin. Psychol. 2, 51-81.

Brown, R. G., and Marsden, C. D. (1991). Dual task performance and processing resources in normal subjects and patients with Parkinson's disease. Brain 114, 215-231.
Brück, A., Aalto, S., Nurmi, E., Bergman, J., and Rinne, J. O. (2005). Cortical 6-[18F]fluoro-L-dopa uptake and frontal cognitive functions in early Parkinson's disease. Neurobiol. Aging 26, 891-898.

Carter, C. S., Macdonald, A. M., Botvinick, M., Ross, L. L., Stenger, V. A., Noll, D., and Cohen, J. D. (2000). Parsing executive processes: strategic vs. evaluative functions of the anterior cingulate cortex. Proc. Natl. Acad. Sci. U.S.A. 97, 1944-1948.

Carter, C. S., Mintun, M., and Cohen, J. D. (1995). Interference and facilitation effects during selective attention: an H152O PET study of Stroop task performance. Neuroimage 2, 264-272.

Carey, R. J., Dai, H., Huston, J. P., Pinheiro-Carrera, M., Schwarting, R. K., and Tomaz, C. (1995). LDOPA metabolism in cortical and striatal tissues in an animal model of parkinsonism. Brain Res. Bull. 37, 295-299.

Charidimou, A., Seamons, J., Selai, C., and Schrag, A. (2011). The role of cognitive-behavioural therapy for patients with depression in Parkinson's disease. Parkinsons Dis. 2011, 737523.

Cohen, J. D., Botvinick, M., and Carter, C. S. (2000). Anterior cingulate and prefrontal cortex: who's in control? Nat. Neurosci. 3, 421-423.

Cohen, J. D., Dunbar, K., and McClelland, J. L. (1990). On the control of automatic processes: a parallel distributed processing account of the Stroop effect. Psychol. Rev. 97, 332-361.

Cools, R., Barker, R. A., Sahakian, B. J., and Robbins, T. W. (2001). Enhanced or impaired cognitive function in Parkinson's disease as a function of dopaminergic medication and task demands. Cereb. Cortex 11, 1136-1143.

Dobkin, R. D., Allen, L. A., and Menza, M. (2007). Cognitve-behavioral therapy for depresión in Parkinson's disease; a pilot study. Mov. Disord. 22, 946-952.

Doder, M., Jahanshahi, M., Turjanski, N., Moseley, I. F., and Lees, A. J. (1999). Parkinson's syndrome after closed head injury: a single case report. J. Neurol. Neurosurg. Psychiatr. 66, 380-385.

Dubois, B., and Pillon, B. (1997). Cognitive deficits in Parkinson's disease. J. Neurol. 1, 2-8.

Egner, T., and Hirsch, J. (2005). Cognitive control mechanisms resolve conflict through cortical amplification of task-relevant information. Nat. Neurosci. 8, 1784-1790.
Elser, V., Rankenburg, I., and Thibault, P. (2007). Searching with iterated maps. Proc. Natl. Acad. Sci. U.S.A. 104, 418-423.

Fahn, S., and Elton, R. L. (1987). "Members of the UPDRS Development Committee. Unified Parkinson's disease rating scale," in Recent Developments in Parkinson's Disease, eds S. Fahn, C. D. Marsden, D. B. Calne, and M. Goldstein (Florham Park, NJ: Macmillan Health Care Information), 153-164.

Fera, F., Nicoletti, G., Cerasa, A., Romeo, N., Gallo, O., Gioia, M. C., Arabia, G., Pugliese, P., Zappia, M., and Quattrone, A. (2007). Dopaminergic modulation of cognitive interference after pharmacological washout in Parkinson's disease. Brain Res. Bull. 74, 75-83.

Folstein, M. F., Folstein, S. E., and McHugh, P. R. (1975). "Mini-mental state.” A practical method for grading the cognitive state of patients for the clinician. J. Psychiatr. Res. 12, 189-198.

Foltynie, T., Brayne, C., and Barker, R. A. (2002). The heterogeneity of idiopathic Parkinson's disease. J. Neurol. 249, 138-145.

George, M. S., Ketter, T. A., Gill, D. S., Haxby, J. V., Underleider, L. G., Herscovitch, P., and Post, R. M. (1993). Brain regions involved in recognition facial emotion or identity: an oxygen-15 PET study. J. Neuropsychiatry Clin. Neurosci. 5, 384-394.

Goebel, S., Mehdorn, H. M., and Leplow, B. (2010). Strategy instruction in Parkinson's disease: influence on cognitive performance. $\mathrm{Neu}$ ropsychologia 48, 574-580.

Hadland, K. A., Rushworth, M. F., Passingham, R. E., Jahanshahi, M., and Rothwell, J. C. (2001). Interference with performance of a response selection task that has no working memory component: an rTMS comparison of the dorsolateral prefrontal and medial frontal cortex. $J$. Cogn. Neurosci. 13, 1097-1108.

Harrison, B. J., Shaw, M., Yücel, M., Purcell, R., Brewer, W. J., Strother, S. C., Egan, G. F., Olver, J. S., Nathan, P. J., and Pantelis, C. (2005). Functional connectivity during Stroop task performance. Neuroimage 24, 181-191.

Kerns, J. G., Cohen, J. D., Macdonald, A. W., Cho, R. Y., Stenger, V. A., and Carter, C. S. (2004). Anterior cingulated conflict monitoring and adjustments in control. Science 303, 1023-1026.

Klein, R. C., de Jong, B. M., de Vries, J. J., and Leenders, K. L. (2005). Direct comparison between regional cerebral metabolism in progressive supranuclear palsy and Parkinson's disease. Mov. Disord. 20, 1021-1030.

Langenecker, S. A., Nielson, K. A., and Rao, S. M. (2004). fMRI of healthy older adult during Stroop interference. Neuroimage 21, 192-200.

Lefaucheur. (2005). Motor cortex dysfunction revealed by cortical excitability studies in Parkinson's disease: influence of antiparkinsonian treatment and cortical stimulation. Clin. Neurophysiol. 116, 244-253.

Lewis, S. J., Dove, A., Robbins, T. W., Barker, R. A., and Owen, A M. (2008). Striatal contributions to working memory: a functional magnetic resonance imaging study in humans. Eur. J. Neurosci. 19, 755-760.

Liu, X., Banich, M. T., Jacobson, B. L., and Tanabe, J. L. (2006). Functional dissociation of attentional selection within PFC: response and nonresponse related aspects of attentional selection as ascertained by fMRI. Cereb. Cortex 16, 827-834.

MacDonald, A. W. 3rd., Cohen, J. D., Stenger, V. A., and Carter, C. S. (2000). Dissociating the role of the dorsolateral prefrontal and anterior cingulate cortex in cognitive control. Science 288, 1835-1838.

MacLeod, C. M. (1991). Half a century of research on the Stroop effect: an integrative review. Psychol. Bull. 109, 163-203.

MacLeod, C. M., and Dunbar, K. (1988). Training and Stroop-like interference: evidence for a continuum of automaticity. J. Exp. Psychol. Learn. Mem. Cogn. 14, 126-135.

Marié, R. M., Lozza, C., Chavoix, C., Defer, G. L., and Baron, J. C. (2007). Functional imaging of working memory in Parkinson's disease: compensations and deficits. J. Neuroimaging 17, 277-285.

McNamara, P., Durso, R., and Harris, E. (2007). "Machiavellianism" and frontal dysfunction: evidence from Parkinson's disease. Cogn. Neuropsychiatry 12, 285-300.

Milham, M. P., Banich, M. T., Webb, A., Barad, V., Cohen, N. J., Wszalek, T., and Kramer, A. F. (2001). The relative involvement of anterior cingulated and prefrontal cortex in attentional control depends on nature of conflict. Brain Res. Cogn. Brain Res. 12, 467-473.

Milham, M. P., Erickson, K., Banich, M., Kramer, A., Webb, A., and Wszalek, T. (2002). Attentional control in the aging brain: insights from an fMRI study of the stroop task. Brain Cogn. 49, 277-296. 
Monchi, O., Petrides, M., MejiaConstain, B., and Strafella, A. P. (2007). Cortical activity in Parkinson's disease during executive processing depends on striatal involvement. Brain 130, 233-344.

Montgomery, S. A., and Asberg, M. (1979). A new depression scale designed to be sensitive to change. Br. J. Psychiatry 134, 382-389.

Morris, R. G., Downes, J. J., Sahakian, B. J., Evenden, J. L., Heald, A., and Robbins, T. W. (1988). Planning and spatial working memory in Parkinson's disease. J. Neurol. Neurosurg. Psychiatry 51, 757-766.

Owen, A. M. (2004). Cognitive dysfunction in Parkinson's disease: the role of frontostriatal circuitry. Neuroscientist 10, 525-537.

Owen, A. M., Doyon, J., Dagher, A., Sadikot, A., and Evans, A. C. (1998). Abnormal basal ganglia outflow in Parkinson's disease identified with PET. Implications for higher cortical functions. Brain 121, 949-965.

Pardo, J. V., Pardo, P. J., Janer, K. W., and Raichle, M. E. (1990). The anterior cingulate cortexmediates processing selection in the Stroop attentional conflict paradigm. Proc. Natl. Acad. Sci. U.S.A. 87, 256-569.

Parkinson, J. (1817). An Essay on the Shaking Palsy. London: Printed by Whittingham and Rowland for Shervood, Neeley and Jones.

Peterson, B. S., Skudlarsky, P., Gartemby, J. C., Zhang, H., Anderson, A. W., and Gore, J. C. (1999). An fMRI study of Stroop word-interference: evidence for cingulated subregions subserving multiple distributed attentional systems. Biol. Psychiatry 45, 1237-1258.

Prats, A., Guerra, H., Crespo, M. D., Silvestre, E., Garolera, M., Petit, C., Alonso, S., Fabra, M., Alcaine, S., Perea, M. V., Ladera, V., and Bayés, A. (2011). Blind randomized controlled study of the efficacy of cognitive training in Parkinson's disease. Mov. Disord. 26, 1251-1258.

Rand, D., Eng, J. J., Liu-Ambrose, T., and Tawashy, A. E. (2010). Feasibility of a 6-month exercise and recreation program to improve executive functioning and memory in individuals with chronic stroke. Neurorehabil. Neural Repair 24, 722-729.

Rektorová, I., Rektor, I., Bares, M., Dostál, V., Ehler, E., Fanfrdlová, Z., Fiedler, J., Klajblová, H., Kulisták, P., Ressner, P., Svátová, J., Urbánek, K., and Velísková, J. (2005). Cognitive performance in people with Parkinson's disease and mild or moderate depression: effects of dopamine agonists in an add-on to L-dopa therapy. Eur. J. Neurol. 2, 9-15.

Rushworth, M. F., Passingham, R. E., and Nobre, A. C. (2002). Components of switching intentional set. $J$. Cogn. Neurosci. 14, 1139-1150.

Sammer, G., Reuter, I., Hullmann, K., Kaps, M., and Vaitl, D. (2006). Training of executive functions in Parkinson's disease. J. Neurol. Sci. 248, 115-119.

Scatton, B., Javoy-Agid, F., Rouquier, L., Dubois, B., and Agid, Y. (1983). Reduction of cortical dopamine, noradrenaline, serotonin and their metabolites in Parkinson's disease. Brain Res. 275, 321-328.

Schiffer, R. B., Kurlan, R., Rubin, A., and Boer, S. (1988). Evidence for atypical depression in Parkinson's disease. Am. J. Psychiatry 145, 1020-1022.

Scholes, K. E., Harrison, B. J., O’Neill, B. V., Leung, S., Croft, R. J., Pipingas, A., Phan, K. L., and Nathan, P. J. (2007). Acute serotonin and dopamine depletion improves attentional control: findings from the stroop task. Neuropsychopharmacology 32, 1600-1610.

Schroeder, U., Kuehler, A., Haslinger, B., Erhard, P., Fogel, W., Tronnier, V. M., Lange, K. W., Boecker, H., and Ceballos-Baumann, A. O. (2002). Subthalamic nucleus stimulation affects striato-anterior cingulate cortex circuit in a response conflict task: a PET study. Brain 125, 1995-2004.

Sinforiani, E., Banchieri, L., Zucchella, C., Pacchetti, C., and Sandrini, G.
(2004). Cognitive rehabilitation in Parkinson's disease. Arch. Gerontol. Geriatr. Suppl. 9, 387-391.

Stam, C. J., Visser, S. L., Op de Coul, A. A., De Sonneville, L. M., Schellens, R. L., Brunia, C. H., de Smet, J. S., and Gielen G. (1993). Disturbed frontal regulation of attention in Parkinson's disease. Brain 116, 1139-1158.

Stroop, J. R. (1935). Studies of interferences in serial verbal reactions. $J$. Exp. Psychol. 18, 643-662.

Talairach, J., and Tournoux, P. (1988). Co-Planar Stereotaxic Atlas of the Human Brain: 3-Dimensional Proportional System - An Approach to Cerebral Imaging. New York: Thieme Medical Publishers.

Tweedy, J. R., Langer, K. G., and McDowell, F. H. (1982). The effect of semantic relations on the memory deficit associated with Parkinson's disease. J. Clin. Neuropsychol. 4, 235-247.

van Veen, V., and Carter, C. S. (2005). Separating semantic conflict and response conflict in the Stroop task: a functional MRI study. Neuroimage 27, 497-504.

Vanderhasselt, M. A., De Raedt, R., Baeken, C., Leyman, L., and D'haenen, H. (2006). The influence of rTMS over the left dorsolateral prefrontal cortex on Stroop task performance. Exp. Brain Res. 169, 279-282.

Vera-Cuesta, H., Vera-Acosta, H. Alvarez-González, L., FernándezMaderos, I., and CasabonaFernández, E. (2006). Frontal dysfunction in idiopathic Parkinson's disease. Rev. Neurol. 42, 76-84.

Vriezen, E. R., and Moscovitch, M. (1990). Memory for temporal order and conditional associative-learning in patients with Parkinson's disease. Neuropsychologia 282, 1283-1293.

Wade, D. T., Gage, H., Owen, C. Trend, P., Grossmith, C., and Kaye, J. (2003). Multidisciplinary rehabilitation for people with Parkinson's disease: a randomised controlled study. J. Neurol. Neurosurg. Psychiatr. 74, 158-162.

Whalen, P. J., Bush, G., McNally, R. J., Wilhelm, S., McInerney, S. C., Jenike, M. A., and Rauch, S. L. (1998). The emotional counting Stroop paradigm: a functional magnetic resonance imaging probe of the anterior cingulate affective division. Biol. Psychiatry 44, 1219-1228.

Williams-Gray, C. H., Hampshire, A., Barker, R. A., and Owen, A. M. (2008). Attentional control in Parkinson's disease is dependent on COMT val 158 met genotype. Brain 131, 397-408.

Zgaljardic, D. J., Borod, J. C., Foldi, N. S., and Mattis, P. (2003). A review of cognitive and behavioural sequelae of Parkinson's disease: relationship to frontoestriatal circuit. Cogn. Behav. Neurol. 16, 193-210.

Conflict of Interest Statement: The authors declare that the research was conducted in the absence of any commercial or financial relationships that could be construed as a potential conflict of interest.

Received: 07 August 2011; accepted: 23 November 2011; published online: 22 December 2011.

Citation: Nombela C, Bustillo PJ, Castell PF, Sanchez L, Medina $V$ and Herrero MT (2011) Cognitive rehabilitation in Parkinson's disease: evidence from neuroimaging. Front. Neur. 2:82. doi: 10.3389/fneur.2011.00082

This article was submitted to Frontiers in Movement Disorders, a specialty of Frontiers in Neurology.

Copyright (c) 2011 Nombela, Bustillo, Castell, Sanchez, Medina and Herrero. This is an open-access article distributed under the terms of the Creative Commons Attribution Non Commercial License, which permits non-commercial use, distribution, and reproduction in other forums, provided the original authors and source are credited. 